www.jmscr.igmpublication.org

Index Copernicus Value: 79.54

ISSN (e)-2347-176x ISSN (p) 2455-0450

crossrefDOI: https://dx.doi.org/10.18535/jmscr/v7i2.79

\title{
Efficacy of tranexamic acid in reducing blood loss during and after Transhiatal Oesophagectomy
}

\author{
Authors \\ Nadeem Ul Nazeer ${ }^{1}$, Ghulam Nabi Lone ${ }^{2}$, Hakeem Zubair Ashraf ${ }^{3}$, Abdul Majeed Dar ${ }^{4}$, \\ Mohammad Akbar Bhat ${ }^{5}$, Farooq A Ganie ${ }^{6}$, Syed Abdul Wahid ${ }^{7}$, Haroon R Naqshi \\ Department of CVTS, Sher-i-Kashmir Institute of Medical Sciences (SKIMS) Soura, Srinagar, Kashmir, \\ India, 190011 \\ *Corresponding Author \\ Dr Nadeem UI Nazeer \\ Post MCh Senior Resident, Department of CVTS, SKIMS, Soura, Srinagar, 190011, India \\ Mob no 9419516738, Email: nadeem_kawoosa@yahoo.co.in
}

\begin{abstract}
Background: Transhiatal oesophagectomy is associated with peri and postoperative blood loss. This study was aimed to evaluate the clinical efficacy and safety of tranexamic acid in reducing peri and postoperative blood loss in patients undergoing transhiatal oesophagectomy.

Materials and Methods: A total of 64 patients, who underwent elective transhiatal oesophagectomy were studied. They were divided into two groups. In the study group of 40 , tranexamic acid $10 \mathrm{mg} / \mathrm{kg}$ intravenous was given before starting intra thoracic dissection and the control group did not receive tranexamic acid. Intra and post-operative blood loss, operation time, transfusion of blood products, pre-and post-operative haemoglobin, number of days of hospitalisation and in hospital mortality was studied for both groups.

Results: Tranexamic acid significantly reduced the volume of blood loss during the surgery when compared with the control group. Considering the duration of operation and the treatment groups only, the mean total blood loss in the control group was more than that in the tranexamic acid group. There was no difference in the length of hospital stay between the two groups.

Conclusion: The prophylactic administration of tranexamic acid has effectively reduced the blood loss and transfusion needs during transhiatal oesophagectomy without any adverse effects or complication of thrombosis.

Keywords: Tranexamic acid, blood loss, trans hiatal oesophagectomy.
\end{abstract}

\section{Introduction}

Blood transfusions are known to increase complications and morbidity. In order to reduce the amount of bleeding during oesophageal surgery, the technical operative measures and antifibrinolytic agents are required to improve haemostasis. Tranexamic acid (TXA) is a competitive inhibitor of plasminogen activation. Tranexamic acid is an antifibrinolytic agent and its predecessor epsilon aminocaproic acid has been used to treat intra and postoperative bleeding in healthy adults for decades. Tranexamic acid is an inexpensive, easily used and relatively safe drug. It inhibits plasminogen activation and 
plasmin $^{[1]}$ thus retards clot disintegration. TXA has also been reported to be successful in reducing haemorrhage in several surgical procedures including craniofacial surgery ${ }^{[2]}$, knee surgery ${ }^{[3]}$, spine surgery ${ }^{[4]}$, prostrate surgeries ${ }^{[5]}$ and the like besides trauma management. Reports of complications following administration of TXA are uncommon and have not been confirmed by controlled clinical research ${ }^{[6,7]}$. This study was aimed to evaluate the clinical efficacy and safety of tranexamic acid to reduce the blood loss and on the coagulation and fibrinolysis profile during transhiataloesophagectomy.

\section{Material and Methods}

A prospective study of the efficacy of TXA in decreasing blood loss during and after transhiatal oesophagectomy was carried out in our department. It included a total of 64 patients who underwent transhiatal oesophagectomy. They were divided into the study group which received TXA (40 patients) and the control group which did not receive TXA (24 patients). TXA 10 $\mathrm{mg} / \mathrm{kg}$, diluted in $100 \mathrm{ml}$ normal saline was given slowly intravenously over 10 minutes in study group before starting the thoracic dissection. Blood loss was measured as the quantity of blood loss $(\mathrm{ml})$ intra operatively $=$ (weight of used sponges and gauzes during operation + volume of blood sucked in suction container. The drainage was also measured postoperatively as neck drain, bilateral intercostal tubes and an abdominal drain was inserted in all the patients. All patients preoperative and 12th hour postoperative blood samples were analyzed for hemoglobin, hematocrit, platelet count, prothrombin time, liver and renal function tests.

Exclusion criterion were as follows.

1. Allergy to medication (tranexamic acid).

2. Anemia, preoperative hepatic or renal dysfunction, serious cardiac or respiratory disease.

3. Congenital or acquired coagulopathy or a history of deep vein thrombosis/ thromboembolic disease.

\section{Results}

All the patients with histologically proven oesophageal carcinoma, with normal bleeding, clotting and prothrombin time, with no other medical complications were alone included in the study. A blood sample was taken for assessment of haemoglobin ( $\mathrm{Hb})$, haematocrit (CBC), prothrombin time (PT), activated partial thromboplastin time (APTT), liver function tests (LFT), renal function tests (RFT), random glucose (RG), and grouping. Blood pressure, pulse and respiratory rate were periodically monitored from the time of admission to the time of surgery. The procedure was done under general anaesthesia. TXA was given intravenously just before commencement of the thoracic dissection. All patients received fluid replacement to maintain urine output greater than $0.5 \mathrm{~mL} / \mathrm{kg}$ / hour. Packed cell (RBC) transfusion was done when the blood loss was greater than one fourth of the blood volume $(70 \mathrm{~mL} / \mathrm{kg}$ for males, $65 \mathrm{~mL} / \mathrm{kg}$ for females), or the haemoglobin level was less than 8 $\mathrm{g} / \mathrm{dL}$. Blood samples were taken at 12 and/or 48 hours postoperatively for haemoglobin, CBC, PT, and APTT. Blood loss was calculated as the difference in pre and postoperative haemoglobin and hematocrit values. Tranexamic acid significantly reduced the volume of blood lost due to the surgery when compared with the control group $(390 \pm 110$ versus $470 \pm 90)$. Thirty six of the TXA group patients required blood transfusion intra or post-operatively. Thirty two patients of the saline group required blood transfusion due to significant drop in haemoglobin below $8 \mathrm{mg} / \mathrm{dL}$. There was no difference in the length of hospital stay between the two groups. The average drop in haemoglobin was more in control group as compared to the tranexamic group. No adverse reactions or thromboembolic events were observed in any of the group. 
Table 1: Demographic profile, preoperative hemoglobin and coagulation parameters

\begin{tabular}{|l|c|c|}
\hline Parameters & TXA Group $(\mathrm{n}=40)$ & Non TXA Group $(\mathrm{n}=24)$ \\
\hline Mean Age (years) & $57.9 \pm 10.1$ & $56.3 \pm 11.6$ \\
\hline Weight $(\mathrm{kg})$ & $61.5 \pm 11.4$ & $62.4 \pm 12.2$ \\
\hline Type of surgery & Transhiatalesophagectomy & Transhiatalesophagectomy \\
\hline Duration of surgery $(\mathrm{min})$ & $165 \pm 28$ & $172 \pm 24$ \\
\hline Hemoglobin $(\mathrm{g} \mathrm{dL}-1)$ & $11.3 \pm 2.8$ & $10.7 \pm 2.5$ \\
\hline Platelet count $\left(\mathrm{x} 10^{3} \mathrm{u} / \mathrm{L}\right)$ & $175 \pm 42$ & $172 \pm 44$ \\
\hline Prothrombin time $(\mathrm{sec})$ & $12.6 \pm 0.8$ & $12.8 \pm 1.1$ \\
\hline
\end{tabular}

Table 2: Comparative values of measured blood loss, blood transfusions, hemoglobin and coagulation profile:

\begin{tabular}{|l|c|c|}
\hline Parameters & TXA Group & Non TXA Group \\
\hline Measured blood loss (ml) & $390 \pm 110$ & $470 \pm 90$ \\
\hline Blood transfusions & 36 & 32 \\
\hline Postoperative haemoglobin & $9.8 \pm 2.2$ & $9.1 \pm 2.5$ \\
\hline Postop hematocrit & $29.3 \pm 2.8$ & $27.3 \pm 2.8$ \\
\hline Postop platelet count & $166 \pm 34$ & $146 \pm 32$ \\
\hline Postop prothrombin time & $13.3 \pm 2.1$ & $13.9 \pm 0.8$ \\
\hline
\end{tabular}

\section{Discussion}

Though the safety and the efficacy of the drug have been established, there is no consensus about the dosage and the best time for administration of this drug. The prescribed dosage is 1-1.5 $\mathrm{g}$ or 15$25 \mathrm{mg} / \mathrm{kg} \mathrm{2-4}$ times daily. The dosage of TXA advocated ranges from $1 \mathrm{gm}^{[8]}$ to $100 \mathrm{mg} / \mathrm{kg}$ transfused over 15 minutes with a second infusion of $10 \mathrm{mg} / \mathrm{kg} / \mathrm{hour}$ transfused until wound closure is achieved ${ }^{[9]}$. Larger doses does not provide additional haemostatic benefit ${ }^{[10]}$. Since TXA has a plasma half-life of 1.9 hours, ${ }^{[11]}$ and our anticipated duration of surgery averaged two to three hours, a dose of $10 \mathrm{mg} / \mathrm{kg}$ weight was chosen as the dosage to maintain a therapeutically effective concentration between $5 \mathrm{mg} / \mathrm{dl}$. Approximately about 55\% of TXA remains in circulation upto 24 hours $^{[12]}$. There was no significant difference in demographic data between groups. No significant difference was present between groups in mean hemoglobin, hematocrit, platelet count, and coagulation parameters. All surgeries were done under general anesthesia and standardized anesthetic technique was used for all patients of both groups. The total measured blood loss $(390 \pm 110)$ in tranexamic acid group was significantly less than control group $(470 \pm 90 \mathrm{~mL})$. The need for blood transfusion was more in the control group. There were no clinically relevant differences in the vital signs in patients following tranexamic acid administration and no thromboembolic complications were detected in either group during hospitalization.

\section{Conflict of interest: None}

\section{References}

1. Cap AP, Baer DG, Orman JA, Aden J, Ryan K, Blackbourne LH. Tranexamic acid fortrauma patients: a critical review of the literature. J Trauma. 2011;71(1Suppl):S914. Review.

2. Maugans TA, Martin D, Taylor J, Salisbury $\mathrm{S}$, Istaphanous $\mathrm{G}$. Comparative analysis of tranexamic Acid use in minimally invasive versus open craniosynostosis procedures. $\mathrm{J}$ Craniofac Surg. 2011;22(5):1772-8.

3. Sa-Ngasoongsong $\mathrm{P}$, Channoom $\mathrm{T}$, Kawinwonggowit V, Woratanarat P, Chanplakorn P, Wibulpolprasert B, et al. Postoperative blood loss reduction in computer-assisted surgery total knee replacement by low dose intra-articular tranexamic acid injection together with 2hour clamp drain: a prospective tripleblinded randomized controlled trial. Orthop Rev (Pavia). 2011;3(2):e12. 
4. Endres S, Heinz M, Wilke A. Efficacy of tranexamic acid in reducing blood loss in posterior lumbar spine surgery for degenerative spinal stenosis with instability: a retrospective case control study. BMC Surg. 2011;11(1):29.

5. Crescenti A, Borghi G, Bignami E, Bertarelli G, Landoni G, CasiraghiGM, et al. Intraoperative use of tranexamic acid to reduce transfusion rate in patients undergoing radical retropubic prostatectomy: double blind, randomised, placebo controlled trial. BMJ. 2011;343:d5701.

6. Verstraete M. Clinical application of inhibitors of fibrinolysis. Drugs. 1985;29:236.

7. Hiippala ST, Strid LJ, Wennerstrand MI, et al. Tranexamic acid radically decreases blood loss and transfusions associated with total knee arthroplasty. AnesthAnalg. 1997;84:839.

8. Zellin G, Rasmusson L, Palsson $\mathrm{J}$, et al. Evaluation of hemorrhage depressors on blood loss during orthognathic surgery: A retrospective study. J Oral Maxillofac Surg. 2004;62:662.

9. Sethna NF, Zurakowski D, Brustowicz RM, et al. Tranexamic acid reduces intraoperative blood loss in pediatric patients undergoing scoliosis surgery. Anesthesiology. 2005;102:727.

10. Horrow JC, Van Riper DF, Strong MD, et al. The dose-response relationship of tranexamic acid. Anesthesiology. 1995;82:383.

11. Eriksson O, Kjellman H, Pilbrant A, et al. Pharmacokinetics of tranexamic acid after intravenous administration to normal volunteers. Eur J ClinPharmacol. 1974;7:375.

12. Pilbrant A, Schannong M, Vessman J. Pharmacokinetics and bioavailability of tranexamic acid. Eur J ClinPharmacol. 1981;20:65. 